\title{
The calibration of the sprayers and the factors involved in coverage uniformity in the vineyard
}

\author{
Davide Mosetti ${ }^{1, *}$, Paolo Sivilotti ${ }^{2}$ and Giovanni Bigot $^{1}$ \\ ${ }^{1}$ Perleuve srl, 34071 Cormons, Italy \\ ${ }^{2}$ University of Udine, Department of Agricultural, Food, Environmental and Animal Sciences, 33100 Udine, Italy
}

\begin{abstract}
The phytopathological condition of the vineyard and the reduction in the use of crop protection products are closely linked to the efficiency of the use of sprayers. The objective of the work was to identify the best operative conditions to improve the canopy coverage of the spraying. From 2012 to 2017173 field trials were carried out in 40 farms, on 24 varieties, testing 72 different sprayers in North Eastern Italy. Water-sensitive papers of $2.5 \times 2.5 \mathrm{~cm}$ were positioned in eight points in the vine canopy according to a standardized method, and they were examined after spraying for spray deposition. In general, results showed that coverage of the lower leaf surface was very poor. On the contrary, the upper section of leaves in the outer canopy layers have received excessive spraying, over $70 \%$ coverage in $25 \%$ of cases. The coverage uniformity was improved by using driving speeds lower than $6 \mathrm{~km} / \mathrm{h}$ and using upward air flow direction.
\end{abstract}

\section{Introduction}

Sprayer calibration is required in viticulture to obtain an even distribution of active substances and canopy coverage, avoiding drift and environmental pollutions [1]. Not casually, Directive 2009/128/EC on sustainable use of pesticides put the attention on sprayer functional control and calibration according to farming typology.

In Friuli Venezia Giulia, North-Eastern Italy, the most important economical disease is Downy mildew Plasmopara viticola (Berl. \& De Toni).

Leaf infections start from stomata, located in the abaxial leaf part. Consequently, the coverage of the underside of the leaf is crucial for maximizing the efficacy of spaying strategies [2].

Among different work parameters for spraying set-up, water volume is very important. It is demonstrated that the application of the correct water volume according to canopy architecture improves the efficacy of the same active substance not only against downy mildew but also against powdery mildew, moths and various other pests and diseases [3].

Thus, the aim of this work was to define the best sprayer work settings to improve spraying coverage on the vine canopy for the habitual vine vigor and vertical training systems of Friuli Venezia Giulia.

\section{Materials and methods}

Within a wide program of integrated pest management aimed to reduce the use of pesticides in the vineyard, the calibration of sprayers was taken into account to improve the distribution in the field.

Between 2012 and 2017 several field tests were carried out Friuli Venezia Giulia, in order to assess the spraying deposition at farm scale. For this purpose, yellow water-sensitive papers were used to evaluate spraying deposition on the vine canopy.

The method involves the use of $2.5 \times 2.5 \mathrm{~cm}$ papers manually clipped on randomly selected leaves of 10 representative vines per trial. The papers were placed in different positions in the canopy, to understand the spraying deposition in the Upper (U) and Lower (L) part of the canopy, in the Outside (O) and Inside (I) leaf layers, and to consider also the different coverage of the Abaxial (B) and Adaxial (D) leaf surface (fig. 1).

The tests were carried out in different vineyards, with different varieties and different sprayers (tab. 1).

\subsection{Statistical analysis}

One-way or two-ways ANOVA was applied and when significant, means were separated using SNK-test $(\mathrm{P}<0.05)$. 

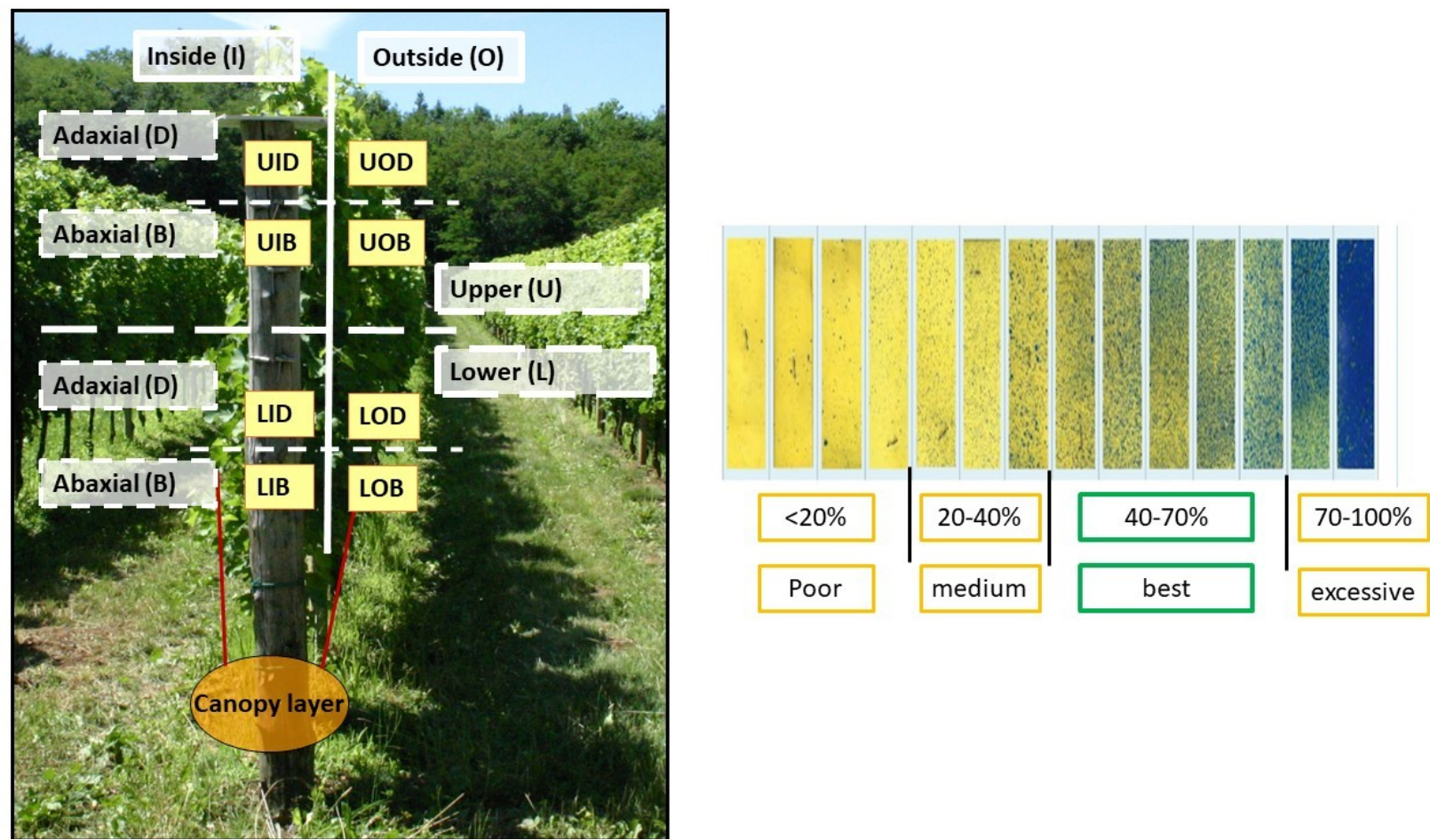

Fig. 1. Placement of yellow water-sensitive papers within the canopy (left). Canopy has been divided into Upper (U) and Lower (L) sections, in the Outside (O) and Inside (I) leaf layers, and Abaxial (B) and Adaxial (D) leaf surface; acronyms of the yellow watersensitive paper positions are: UOD - Upper part of the canopy, Outside leaf layer, aDaxial leaf surface, UOB - Upper part of the canopy, Outside leaf layer, aBaxial leaf surface, UID - Upper part of the canopy, Inside leaf layer, aDaxial leaf surface, UIB - Upper part of the canopy, Inside leaf layer, aBaxial leaf surface, LOD - Lower part of the canopy, Outside leaf layer, aDaxial leaf surface, LOB - Lower part of the canopy, Outside leaf layer, aBaxial leaf surface, LID - Lower part of the canopy, Inside leaf layer, aDaxial leaf surface, LIB - Lower part of the canopy, Inside leaf layer, aBaxial leaf surface. In the right section, classes of the spraying deposition according to the percentage of coverage are defined.

Table 1. Detail of the field trials carried out during the years 2012-17.

\begin{tabular}{|c|c|}
\hline Farms & 40 \\
\hline Vineyards & 78 \\
\hline Varieties & 24 \\
\hline Sprayers & 72 \\
\hline Trials & 173 \\
\hline Water-sensitive papers used & 9812 \\
\hline
\end{tabular}

\section{Results and Discussion}

The great amount of data collected along the five years of measurement of spray depositions, allowed us to undergo through several different analyses of the processed data. In an attempt to show a general result, all sprayer typologies were compared examining the spray deposition in the lower and upper part of the canopy, outside and inside the canopy, and on the abaxial and adaxial leaf surface (tab. 2). In the lower part of the canopy the adaxial leaf surface is more covered than average. On the contrary, in $49 \%$ of cases (486/990 of leaves checked for LIB position), the abaxial leaf surface is covered poorly (less than $20 \%$, according to the classes explained in fig.1).

The upper part of the canopy generally presents a more even spray deposition between the abaxial and adaxial surface of the leaves, and this can be related to the smaller number of leaf layers that facilitates leaves to be intercepted by pesticide flux.

Among the operative conditions affecting spraying uniformity, it is very important the role of applied water volume. In our dataset, four classes of water volume were distinguished (tab. 3), and statistical analysis was applied to check the differences. Limited water volumes (less than $300 \mathrm{~L} / \mathrm{ha}$ ) resulted in a spray deposition significantly lower than in case of higher volumes (tab. 3). To date, the best results were shown with volumes ranging between 300 and $400 \mathrm{~L} /$ ha while higher volumes, resulted in excessive liquid dropping on the paper surfaces.

Table 2. Average percentage of spray deposition in different parts of the canopy and on the adaxial/abaxial leaf surfaces.

\begin{tabular}{|c|l|c|}
\hline canopy position & \multicolumn{1}{|c|}{$\begin{array}{c}\text { leaf } \\
\text { surface }\end{array}$} & $\begin{array}{c}\text { Spray } \\
\text { deposition } \\
\mathbf{\%}\end{array}$ \\
\hline \multirow{2}{*}{ upper } & adaxial & 32,2 \\
\cline { 2 - 3 } & abaxial & 34,2 \\
\hline \multirow{2}{*}{ lower } & adaxial & 45,4 \\
\cline { 2 - 3 } & abaxial & 29,4 \\
\hline
\end{tabular}


Tab. 3. Effect of water volume applied on the spraying deposition checked in the water-sensitive papers. Detail of the field trials carried out during the years 2012-17. Data processed through one-way ANOVA $(* * *, p<0.001)$ and means separated with SNK-test $(\mathrm{p}<0.05)$.

\begin{tabular}{|r|c|}
\hline$<200 \mathrm{~L} / \mathrm{ha}$ & $27,16 \mathrm{c}$ \\
\hline $200-300 \mathrm{~L} / \mathrm{ha}$ & $34,31 \mathrm{~b}$ \\
\hline $300-400 \mathrm{~L} / \mathrm{ha}$ & $38,87 \mathrm{a}$ \\
\hline $400-500 \mathrm{~L} / \mathrm{ha}$ & $37,42 \mathrm{a}$ \\
\hline Sign. $F$ & $* * *$ \\
\hline
\end{tabular}

Going deeper into the comparisons and correlating the spray deposition on the abaxial and adaxial leaf surface as related with the applied water volume, different results arose. In detail, a good positive correlation was found for adaxial leaf surface, while in case of the abaxial leaf surface other factors have to be considered more crucial in order to improve the spray deposition (fig. 2).

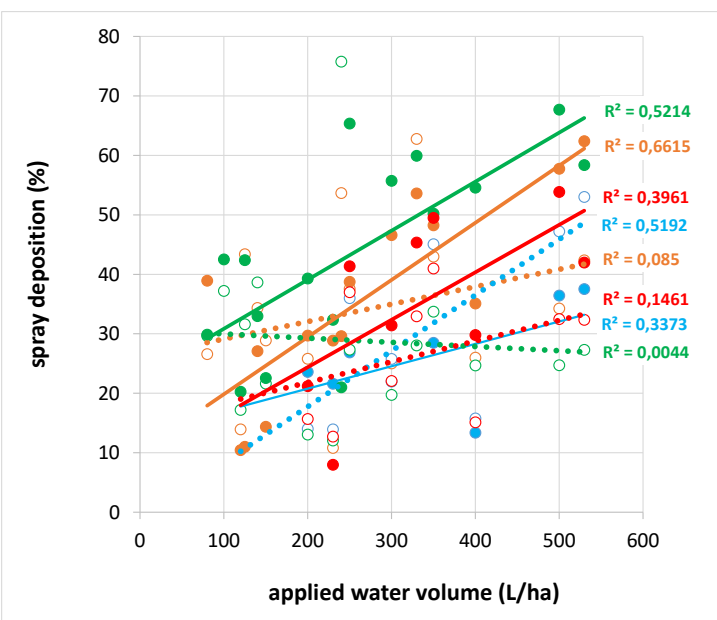

Fig. 2. Correlations between applied water volume and spraying deposition on the adaxial (solid lines) and abaxial leaf surfaces (dotted lines). The colors indicated the different positions in the canopy: green (LOD and LOB); red (LID and LIB); orange (UOD and UOB); blue (UID and UIB).

Another important factor to be taken into account is the tractor driving speed. Differently from above, the spray deposition on the adaxial surface of the leaves is not correlated with the tractor speed, while a negative correlation was observed when considering the abaxial surfaces of the leaves. With the aim of obtaining a good spray deposition on the abaxial leaf surfaces, the tractor should not surpass $6 \mathrm{~km} / \mathrm{h}$ driving speed (Fig. $3)$.

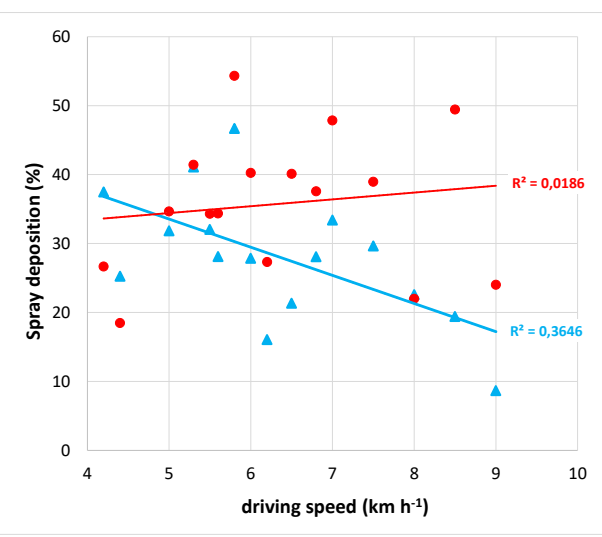

Fig. 3. Correlations between driving speed and spraying deposition on the adaxial (red circles and line) and abaxial leaf surfaces (blue triangles and line).

Also, the direction of applied water should be considered when analyzing the spray deposition (Tab. 4). The sprayers with upward flux allowed a better coverage of the abaxial leaf surfaces, while the machines with downward fluxes showed less coverage of leaves in all positions except in LOD (data not reported). The average coverage of the sprayers $U$ (upward flux) and D (downward flux) was lower than in case of $\mathrm{R}$ (radial flux) or $\mathrm{H}$ (horizontal flux). This result can be explained since most of $U$ and $D$ sprayers are nebulizers that normally use lower water volumes, thus less coverage can be expected. The sprayers $\mathrm{H}$ and $\mathrm{R}$ excessively cover the outside leaves positioned in the lower part of the canopy, and they cannot efficiently penetrate the more internal leaves (Tab. 5).

Tab. 4. Effect of flux direction and leaf position on spray deposition. Data processed through two-ways ANOVA (***, $\mathrm{p}<0.001)$ and means separated with SNK-test $(\mathrm{p}<0.05)$.

\begin{tabular}{|c|c|c|}
\hline \multicolumn{2}{|l|}{ factor } & $\begin{array}{c}\text { Spray } \\
\text { deposition } \\
(\%) \\
\end{array}$ \\
\hline \multirow{5}{*}{ flux direction $(F)$} & U (upward flux) & $29.98 \mathrm{c}$ \\
\hline & $\mathrm{D}$ (downward flux) & $29.94 \mathrm{c}$ \\
\hline & H (horizontal flux) & $35.64 \mathrm{~b}$ \\
\hline & R (radial flux) & $37.76 \mathrm{a}$ \\
\hline & sign. $F$ & $* * *$ \\
\hline Leaf position (L) & sign. $F$ & $* * *$ \\
\hline Interaction F x L & sign. $F$ & $* * *$ \\
\hline
\end{tabular}


Tab. 5. Flux direction as affecting the percentage difference between adaxial and abaxial spray deposition in the different positions within the canopy. Acronyms: flux direction: U upward flux, D - downward flux, R - radial flux, H horizontal flux; leaf position: UO - Upper part of the canopy, Outside leaf layer, UI - Upper part of the canopy, Inside leaf layer, LO - Lower part of the canopy, Outside leaf layer, LI Lower part of the canopy, Inside leaf layer. Lower values account for a higher coverage of the abaxial leaf surfaces. Conditional formatting was applied to highlight the low (blue) and high values (red).

\begin{tabular}{|c|c|c|c|c|}
\hline & UO & UI & LO & LI \\
\hline U & $-70,7$ & $-194,7$ & 16,7 & $-33,7$ \\
\hline $\mathrm{D}$ & 16,9 & $-22,0 \%$ & 40,4 & 24,0 \\
\hline $\mathrm{H}$ & 24,1 & $-23,2$ & 57,3 & 24,2 \\
\hline $\mathrm{R}$ & 0,4 & $-71,3$ & 43,9 & 16,4 \\
\hline
\end{tabular}

Also in regards to the sprayer typology, we observed several differences. All machines generally cover better the adaxial leaf surfaces in the lower part of the canopy (Tab. 6). Sprayers, recovery-drift machines and nebulizers in general allow a better coverage of the leaves in all positions within the canopy. Dissimilarly, backpack sprayers poorly cover the abaxial surfaces of the leaves. Backpack sprayers' lack of a strong airflow thus does not allow pesticides to reach both leaf surfaces.

Airspeed and airflow are important factors when a grapevine grower has to choose a sprayer.

Tab. 6. Sprayer typology as affecting spray deposition in different positions within the canopy. Acronyms of the yellow watersensitive paper positions are: UOD - Upper part of the canopy, Outside leaf layer, aDaxial leaf surface, UOB - Upper part of the canopy, Outside leaf layer, aBaxial leaf surface, UID - Upper part of the canopy, Inside leaf layer, aDaxial leaf surface, UIB - Upper part of the canopy, Inside leaf layer, aBaxial leaf surface, LOD - Lower part of the canopy, Outside leaf layer, aDaxial leaf surface, LOB - Lower part of the canopy, Outside leaf layer, aBaxial leaf surface, LID - Lower part of the canopy, Inside leaf layer, aDaxial leaf surface, LIB - Lower part of the canopy, Inside leaf layer, aBaxial leaf surface Data were processed through two-ways ANOVA and interaction was significant $(* * *, p<0.001)$. For each machine one-way ANOVA was applied and means were separated with SNK-test $(\mathrm{p}<0.05)$.

\begin{tabular}{|c|c|c|c|c|}
\hline & Sprayers & $\begin{array}{c}\text { Recovery drift } \\
\text { sprayers }\end{array}$ & $\begin{array}{c}\text { backpack } \\
\text { sprayers }\end{array}$ & nebulisers \\
\hline UOB & $38,66 \mathrm{bc}$ & $31,67 \mathrm{e}$ & $20,3 \mathrm{c}$ & $27,48 \mathrm{~b}$ \\
\hline UOD & $39,86 \mathrm{~b}$ & $52,97 \mathrm{~b}$ & $88,34 \mathrm{a}$ & $29,27 \mathrm{~b}$ \\
\hline UIB & $35,76 \mathrm{~cd}$ & $37,21 \mathrm{~cd}$ & $19,08 \mathrm{c}$ & $27,22 \mathrm{~b}$ \\
\hline UID & $21,22 \mathrm{f}$ & $37,75 \mathrm{~cd}$ & $45,76 \mathrm{~b}$ & $20,15 \mathrm{c}$ \\
\hline LOB & $29,92 \mathrm{e}$ & $28,4 \mathrm{de}$ & $11,89 \mathrm{c}$ & $20,89 \mathrm{c}$ \\
\hline LOD & $54,04 \mathrm{a}$ & $64,74 \mathrm{a}$ & $93,18 \mathrm{a}$ & $42,31 \mathrm{a}$ \\
\hline LIB & $34,3 \mathrm{~d}$ & $32,61 \mathrm{de}$ & $10,9 \mathrm{c}$ & $20,24 \mathrm{c}$ \\
\hline LID & $39,97 \mathrm{~b}$ & $40,27 \mathrm{c}$ & $58,92 \mathrm{~b}$ & $28,84 \mathrm{~b}$ \\
\hline sign. $F$ & $* * *$ & $* * *$ & $* * *$ & $* * *$ \\
\hline
\end{tabular}

\section{Conclusions}

Summarizing the results, the different operating conditions affected the spray deposition in the different parts of the canopy and between the adaxial and abaxial surface of the leaves. Based on the results reported, a few recommendations could be given in case of vineyards characterized by Vertical Shoot Position (VSP) training systems and medium vigor (average range of 2-2.5 Leaf Layer Number (LLN)) in Friuli Venezia Giulia:

- the applied water volume should be higher than 350 $\mathrm{L} / \mathrm{ha}$ in case of sprayers and higher than $250 \mathrm{~L} / \mathrm{ha}$ in case of nebulizers;

- the max driving speed of the tractor should not surpass $6 \mathrm{~km} \mathrm{~h}^{-1}$;

- to obtain the best spray deposition of the abaxial leaf surface, machines with upward flux direction should be used.
The authors thanks Enzo Mescalchin and his staff of Fondazione Edmund Mach, for the water sensitive paper field method and coverage analysis.

\section{References}

1. E. Gil, J. Llop, M. Gallart, M. Valera, J. Llorens Julius-Kühn-Archiv, 448， 8-9 (2015)

2. C. Gessler, I. Pertot, M. Perazzoli Pythopathol. Mediterr. 50, 3-44 (2011)

3. J. C. Wise, P. E. Jenkins, A. M.C. Schilder, C. Vandervoort, R- Isaacs Crop Prot. 29, 378-385 (2010) 